\title{
X-linked hypophosphataemic rickets in children: clinical phenotype, therapeutic strategies, and molecular background
}

\author{
Monika Obara-Moszynska ${ }^{\circledR 1}$, Aleksandra Rojek ${ }^{\circledR 1}$, Zofia Kolesinska ${ }^{\circledR 1}$, Dorota Jurkiewicz ${ }^{\left({ }^{2}\right.}$, \\ Krystyna H. Chrzanowska ${ }^{\circledR 2}$, Marek Niedziela ${ }^{\circledR 1}$ \\ ${ }^{1}$ Department of Paediatric Endocrinology and Rheumatology, Poznan University of Medical Sciences, Institute of Paediatrics, \\ Poznan, Poland \\ ${ }^{2}$ Department of Medical Genetics, The Children's Memorial Health Institute, Warsaw, Poland
}

\begin{abstract}
Introduction: X-linked hypophosphataemic rickets (XLHR) is the most common form of hypophosphataemic rickets (HR), which is caused by mutations in the PHEX gene. The aim of this work was to investigate the clinical phenotype, therapeutic strategies, and molecular background of HR in children hospitalised in our clinic.

Material and methods: Eleven patients aged 5.7-18.25 years were included in this study. Molecular analysis was performed using polymerase chain reaction (PCR) and direct sequencing. The PHEX gene was examined in all of the patients, whereas the FGF23 gene was analysed in 5 patients. All of them were treated with alphacalcidol and phosphorus, and 3 were additionally treated with recombinant human growth hormone (rhGH).

Results: The mean age at HR diagnosis was $4.05 \pm 3.35$ years. The mean htSDS was $-2.99 \pm 1.19$. In 2 of the 3 patients treated with rhGH the height gain was $+0.4 \mathrm{SD}$ and $+0.3 \mathrm{SD}$, respectively. In 10 of 11 patients, PHEX gene mutations were found. In 2 children, novel mutations in the PHEX gene were identified: c.325_326dupCA, N110Ifs*7 in one patient and c.899_900delTG, M300Kfs*4 in the remaining one, which coexisted with a known polymorphism c.1769-10C > T, rs3752433. In one patient, a novel deletion of exon 14 and 2 polymorphisms were detected: c.1646-46T > C, g.180417T > C, rs3213493 in intron 15 (known) and g.189156C > T in intron 17 (novel).

Conclusion: We report 3 novel mutations in the PHEX responsible for HR. Additionally, this study reports the effects of rhGH therapy for growth promotion in HR. (Endokrynol Pol 2021; 72 (2): 108-119)
\end{abstract}

Key words: hypophosphataemic rickets; hypophosphataemia; PHEX gene; recombinant human growth hormone therapy; rhGH

\section{Introduction}

Hypophosphataemic rickets (HR) belongs to a heterogeneous group of rare diseases that are caused by phosphate deregulation due to excessive renal phosphate wasting and decreased mineralisation of the growth plate in the growing child [1]. The mode of inheritance of HR varies depending on the affected gene, and the clinical manifestations of HR vary in severity. Some patients are minimally affected even in the absence of medical therapy, whereas others suffer from very severe rickets. The predominant skeletal deformities include progressive bowing of the legs, anteromedial rotational torsion of the tibiae, and short stature [2] along with dental, periodontal, and ear problems, which may also occur in patients with HR.

The most common form of HR (1:20,000 births) is X-linked HR(XLHR,X-linked dominant, OMIM\#307800)
[3] caused by mutations in the PHEX gene (OMIM *300550, a phosphate-regulating gene with homology to neutral endopeptidases on the X chromosome) located on the $\mathrm{X}$ chromosome. The XLHR phenotype is characterised mainly by rickets with progressive bone deformities, flaring of the metaphyses, short stature, and dental anomalies [4], and the difference between the phenotypes of affected girls and boys may not be significant. XLHR belongs to FGF23-mediated rickets, where the level of intact FGF23 is increased in the serum. In turn, FGF23 is expressed by osteocytes standing for a key regulator of phosphate reabsorption in the proximal renal tubules and which also inhibits the activity of vitamin $\mathrm{D}$ renal $1 \alpha$-hydroxylase.

Early diagnosis of HR and its treatment with vitamin D and phosphorus supplementation, which is safe for patients, are crucial because they can help reduce the progression of bone deformations, prevent 
severe bone deformities, reduce the number of necessary surgeries, and improve the patient's final height. However, such treatment is not always effective, and careful monitoring to avoid toxicity is mandatory [2, 5]. The above-mentioned conventional treatment is limited by its renal (hypercalciuria, nephrocalcinosis) and gastrointestinal (abdominal pain, diarrhoea) side effects. Moreover, both phosphate and active vitamin D trigger further FGF23 expression in bones, resulting in a vicious circle, which may limit the efficacy and safety of the standard treatment [6]. Current outcomes of this therapy are still not fully satisfactory, and new therapies targeting the pathophysiology of the disease, i.e. FGF23 excess is the goal. In 2018, the US Food and Drug Administration and European Medicines Agency approved burosumab, a human anti-FGF23 monoclonal antibody that appears to be effective for the treatment of XLHR in children aged 1 year and older $[7,8]$. In some cases, HR is diagnosed after infancy and may lead to severe growth deceleration. Recombinant human growth hormone (rhGH) therapy may be used along with supplementation with vitamin $\mathrm{D}$ and phosphorus because, if combined with insulin-like growth factor 1 (IGF-1), this therapy improves longitudinal growth and transiently stimulates phosphate reabsorption [9]. Several studies have shown that treatment with rhGH is able to improve growth in short children with XLHR for treatment periods of up to 3 years [10-13].

In addition to vitamin $\mathrm{D}$ analogues and phosphate supplements that improve tooth mineralisation, oral hygiene, active endodontic treatment of root abscesses, and preventive protection of teeth surfaces are recommended.

\section{The aim of the study}

The aim of this study was to investigate the clinical phenotype, therapeutic outcome, and molecular background of HR in children hospitalised in the Department of Paediatric Endocrinology and Rheumatology, Poznan University of Medical Sciences.

\section{Material and methods}

This study was carried out in accordance with the Declaration of Helsinki and was approved by the local Ethics Committee (Karol Marcinkowski Poznan University of Medical Sciences) (No. 504/13).

\section{Patients}

We analysed 11 patients ( 6 girls and 5 boys) aged $5.7-18.25$ years (mean age $11.63 \pm 4.31$ ), who were diagnosed with HR due to their clinical and biochemical profiles. All of the patients were under care of the Department of Paediatric Endocrinology and Rheumatology, Poznan University of Medical Sciences, and were treated with alphacalcidol and phosphorus. The average period of observation was 4.5 years (range, $0-7.3$ years). Three patients with a diagnosis of growth hormone deficiency were also treated with recombinant human growth hormone (Omnitrope, Sandoz) (Tab. 1).

\section{Methods}

The height standard deviation score (htSDS) for chronological age was calculated using Polish references [14]. Bone age was estimated according to the Greulich and Pyle [15] method, while predicted adult height was calculated in line with the Bayley and Pinneau [16] method.

Blood samples were collected and frozen at $-20^{\circ} \mathrm{C}$ until analysis. Genetic analysis of PHEX and FGF23 was performed in the Molecular Endocrinology Laboratory of the Department of Paediatric Endocrinology and Rheumatology, Poznan University of Medical Sciences, Poland. Routine biochemical measurements were performed in the Central Laboratory of Karol Jonscher's Clinical Hospital of the University using commercial kits. The studies were carried out using the standard polymerase chain reaction (PCR) method and DNA isolated from peripheral blood leucocytes using the QIAamp ${ }^{\circledR}$ DNA Blood Mini Kit (QIAGEN) according to the manufacturer's instructions. Oligonucleotides (Supplementary Table 1) were purchased from GenoMed, and their sequences were published previously [17]. PCRs were performed in $10-\mu$ l volumes using HotStarTaq ${ }^{\circledR}$ DNA Polymerase (QIAGEN) under the following parameters: denaturation at $95^{\circ} \mathrm{C}$ for $15 \mathrm{~min}$, followed by 35 cycles of $95^{\circ} \mathrm{C}$ for $60 \mathrm{~s}$, annealing at $52-62^{\circ} \mathrm{C}$ (depending on the primer pair) for 30 s, and elongation at $72^{\circ} \mathrm{C}$ for $30 \mathrm{~s}$. A final amplification at $72^{\circ} \mathrm{C}$ for 10 min completed the PCR program.

The FGF23 gene was analysed in the selected patients (Patient Nos. 1-5) and amplified using routine PCR and primers that encompass exon/intron sites (Supplementary Table 2) [18].

The PCR products were separated by electrophoresis on a $1 \%$ agarose gel in the presence of ethidium bromide (Merck), purified from the gel using a QIAquick ${ }^{\circledR}$ Gel Extraction Kit (QIAGEN) and directly sequenced on an ABI Prism 3130XL Genetic Analyzer (Applied Biosystems) using a BigDye Terminator v3.1 cycle sequencing kit (Applied Biosystems). Finally, sequences were analysed using Vector NTI 9.0 Software (Invitrogen) and compared to the NCBI Reference Sequences. Bioinformatic analysis of the DNA variants identified in the patients was conducted using Mutation Taster software (http://www.mutationtaster.org/). The DNA variant was annotated as a novel variant when it was not found in ExAC (http://exac.broadinstitute.org/), 1000G (http://www.internationalgenome.org/1000-genomes-browsers/) as well as gnomAD databases (https://gnomad.broadinstitute.org/).

\section{Results}

\section{Clinical findings}

The average time of HR diagnosis was from 1 and $1 / 12$ to 9 years. In four patients (Nos. 2, 8, 9, and 11), rickets was recognised later (from 7 to 9 years), despite their mothers being affected. In all patients examined, deformities of the lower limbs were observed, and the dominant clinical feature was bowing of the legs with genu varum (10/11 patients, 91\%).

In one patient, genu valgum was observed (1/11, $9 \%$ ). The deformities of the lower leg were sometimes associated with other rickets symptoms, such as widening of the distal parts of the forearms, frontal bossing, or hyperlordosis. Characteristic symptoms of rickets in the examined patients are shown in Figure 1. In 4/11 patients $(36 \%)$, periodontal problems were observed: gingivitis in two of the patients and advanced caries in two others. Short stature was observed in 9/11 (81.8\%) patients. The mean htSDS was $-2.99 \pm 1.19(\mathrm{~min}-4.7$, $\max -1.3)$ 


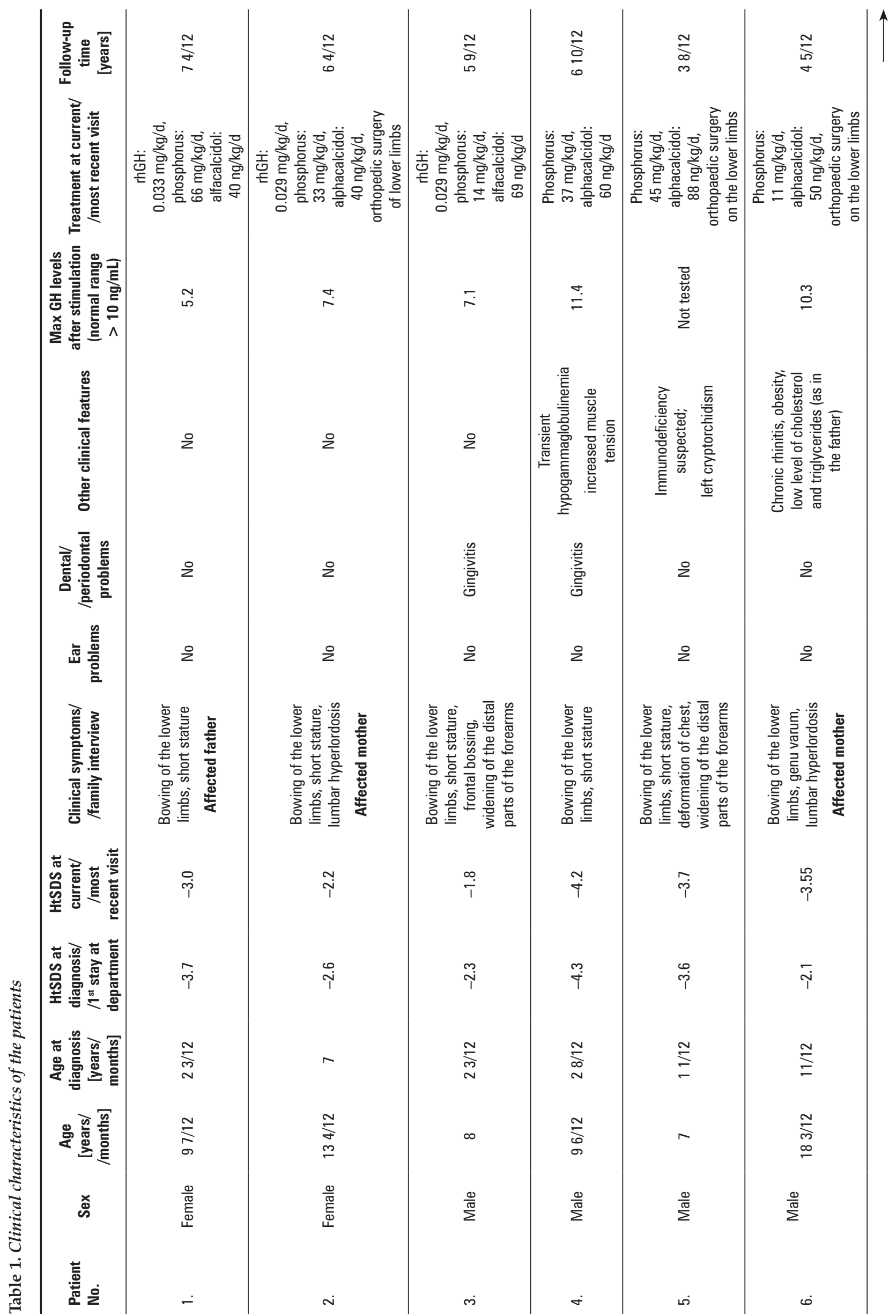




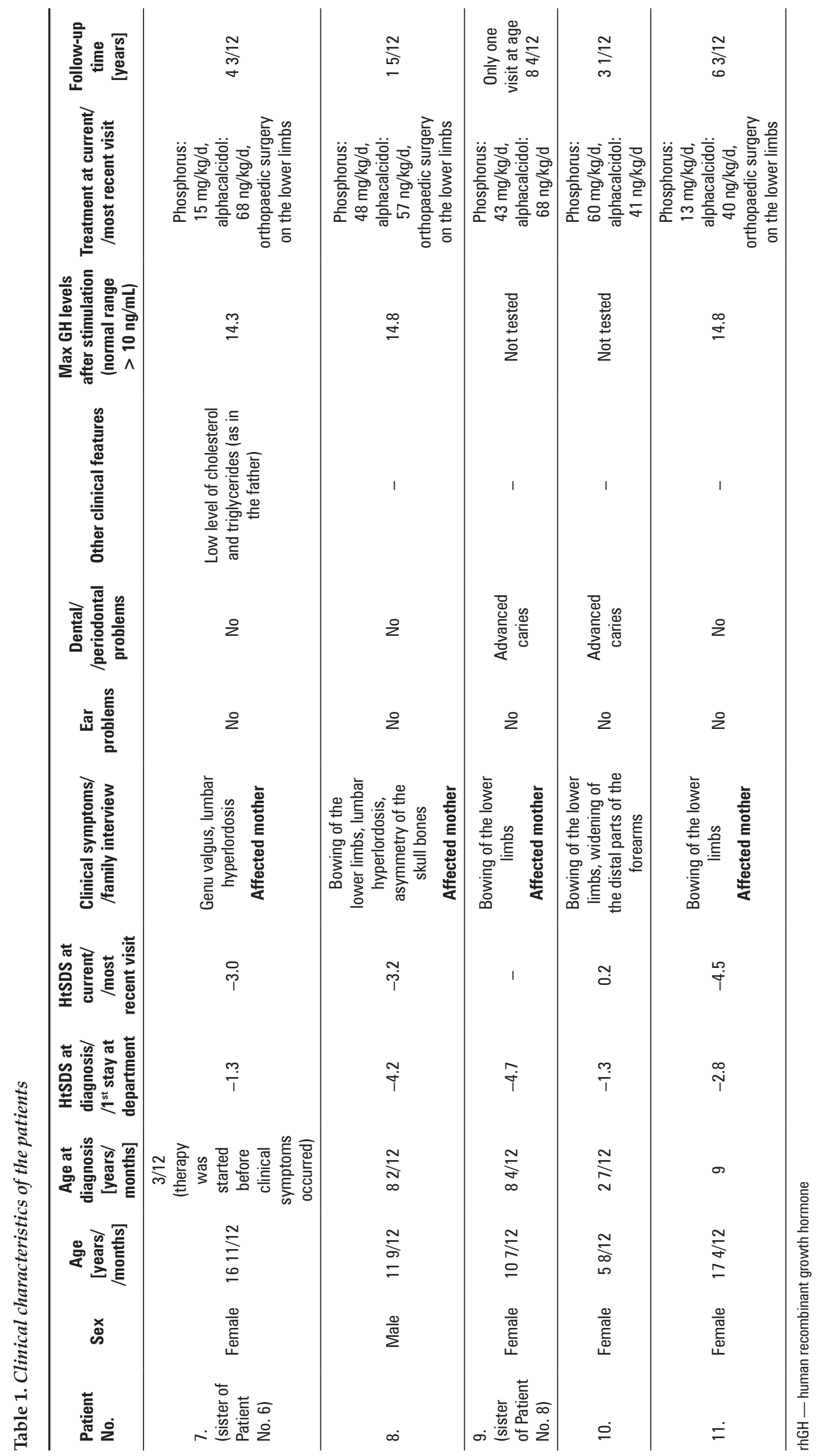



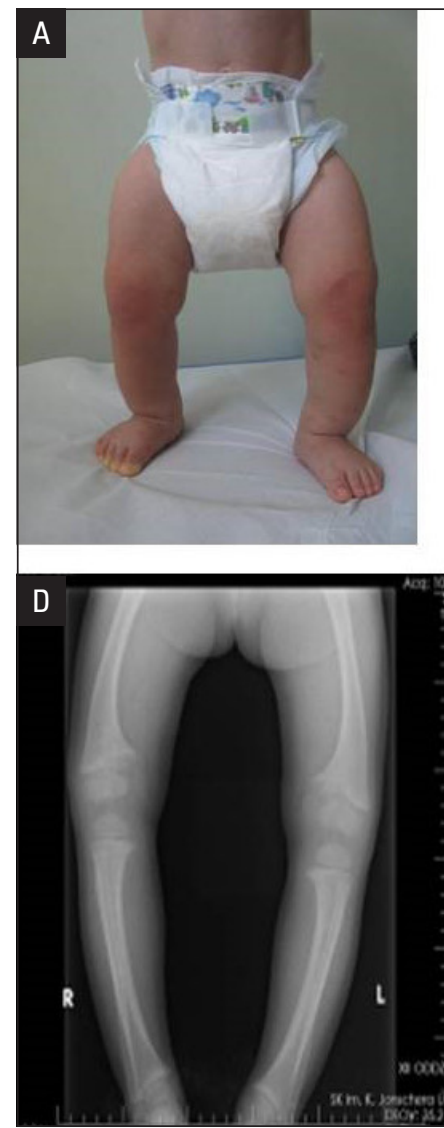
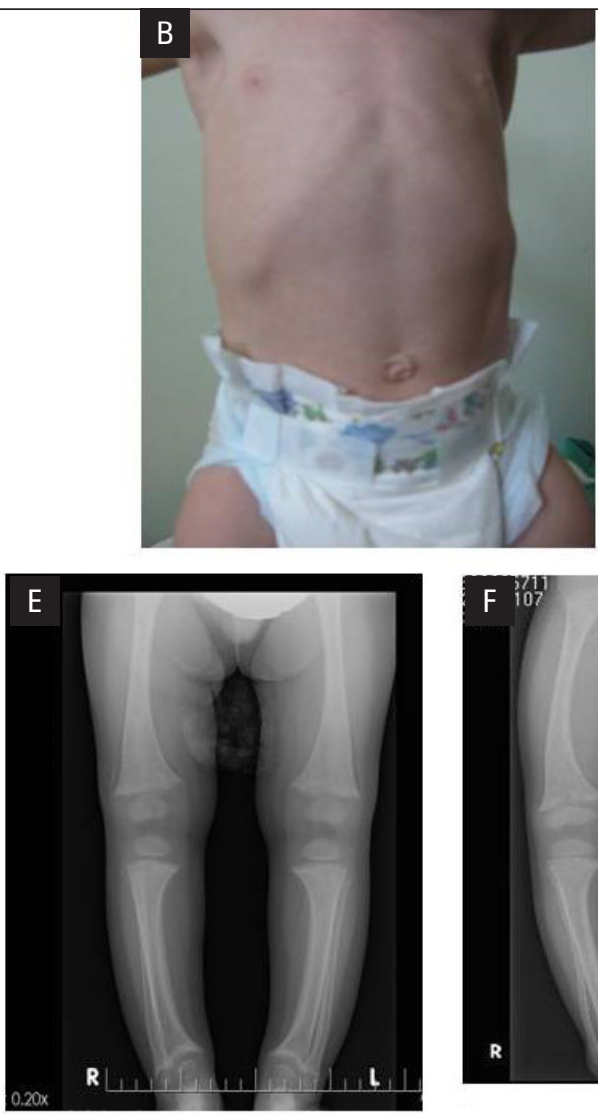
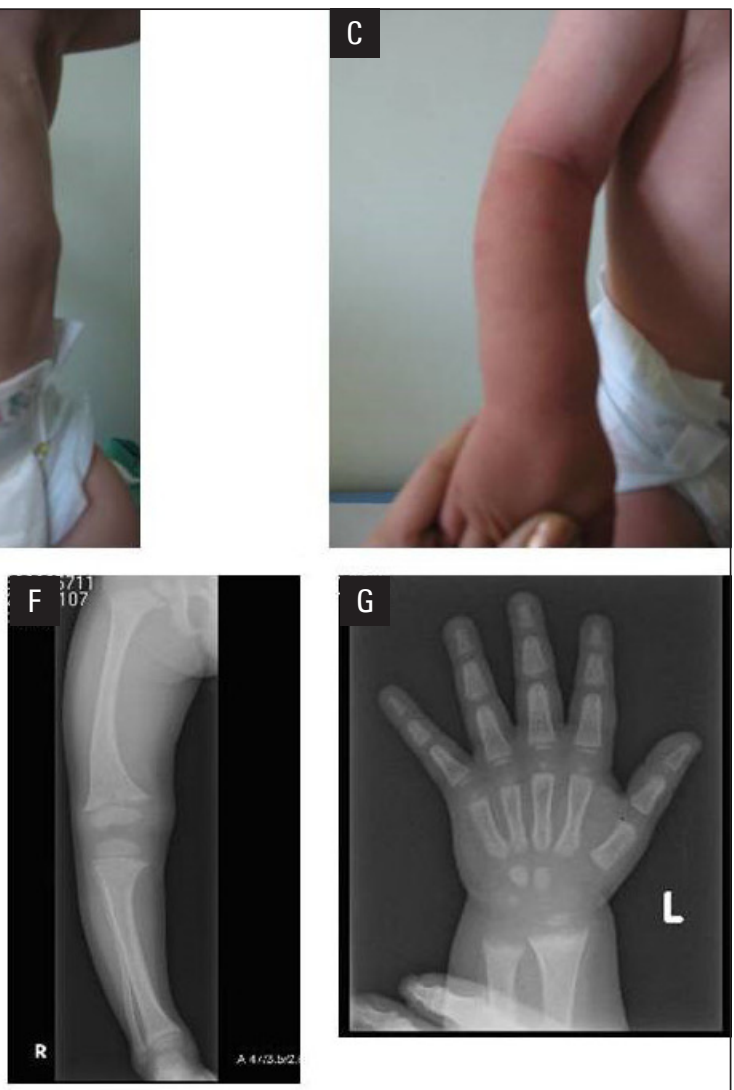

Figure 1. Characteristic symptoms of rickets in the presented patients. Bowing of the lower limbs (A), deformation of the chest (B) and widening of the distal parts of the forearms (C) in Patient No. 5; X-ray of the lower limbs of Patient No. 1 (D), Patient No. 3 (E) and Patient No. 4 (F) at diagnosis, with characteristic bowing of the lower limbs and distal flaring of the long bones; X-ray of the left hand of Patient No. 3 with characteristic widening of the distal parts of the forearms (G)

The clinical characteristics of the studied group are listed in Table 1.

The dominant biochemical abnormality at the time of diagnosis/during the first stay at the department was hypophosphataemia (11/11, 100\% of patients) and high levels of alkaline phosphatase $(10 / 11,90.9 \%)$. In most patients urine phosphorus excretion was decreased $(6 / 11 ; 54.5 \%)$, in 2 patients it was increased $(2 / 11 ; 18.2 \%)$, and in 3 patients it was within the laboratory normal range $(3 / 11,27.3 \%)$. In all patients, tubular reabsorption of phosphate (TRP) at the time of the diagnosis/during the first stay at the department was normal but dropped below the range during follow-up. The concentrations of total calcium, parathyroid hormone, and $25(\mathrm{OH}) \mathrm{D} 3$ (a metabolite of vitamin D3) at diagnosis/during the first stay at the department were within normal ranges in most patients $(10 / 11,90.9 \% ; 8 / 11,72.7 \%$; 10/11, 90.9\%, respectively). Normalisation of alkaline phosphatase during therapy was observed in 6 children $(6 / 11,54.5 \%)$. The biochemical characteristics of the studied patients are presented in the supplementary materials (Supplementary Table 3).
In one patient (No. 3), due to the presence of frontal bossing, MRI of the head was performed, which revealed a Chiari type 1 malformation.

Six children underwent conventional orthopaedic surgery because of advanced deformities of the lower limbs, and in 3 patients (Nos. 1, 3, and 4) improvement of lower limb deformation was observed by applying only pharmacological treatment. The intercondylar distance changed from $12 \mathrm{~cm}$ to $2 \mathrm{~cm}$ in Patient No. 1 (Fig. 2), from 8 to $3 \mathrm{~cm}$ in Patient No. 3, and from 7 to $0 \mathrm{~cm}$ in Patient No. 4. In Patient No. 10 the intercondylar distance, despite an early diagnosis (2 years and 7 months) and 3 years of pharmacological treatment, decreased only from $8 \mathrm{~cm}$ to $5.5 \mathrm{~cm}$, and because of severe bowing of the tibial bones, orthopaedic surgery is planned. In other patients, the effects of pharmacologic treatment were difficult to estimate because they underwent orthopaedic surgery or the clinical observation period at our department was too short.

Three patients (Nos. 1, 2, and 3) are being treated with rhGH because they presented GH deficiency. In two of them, we achieved an improvement in height 


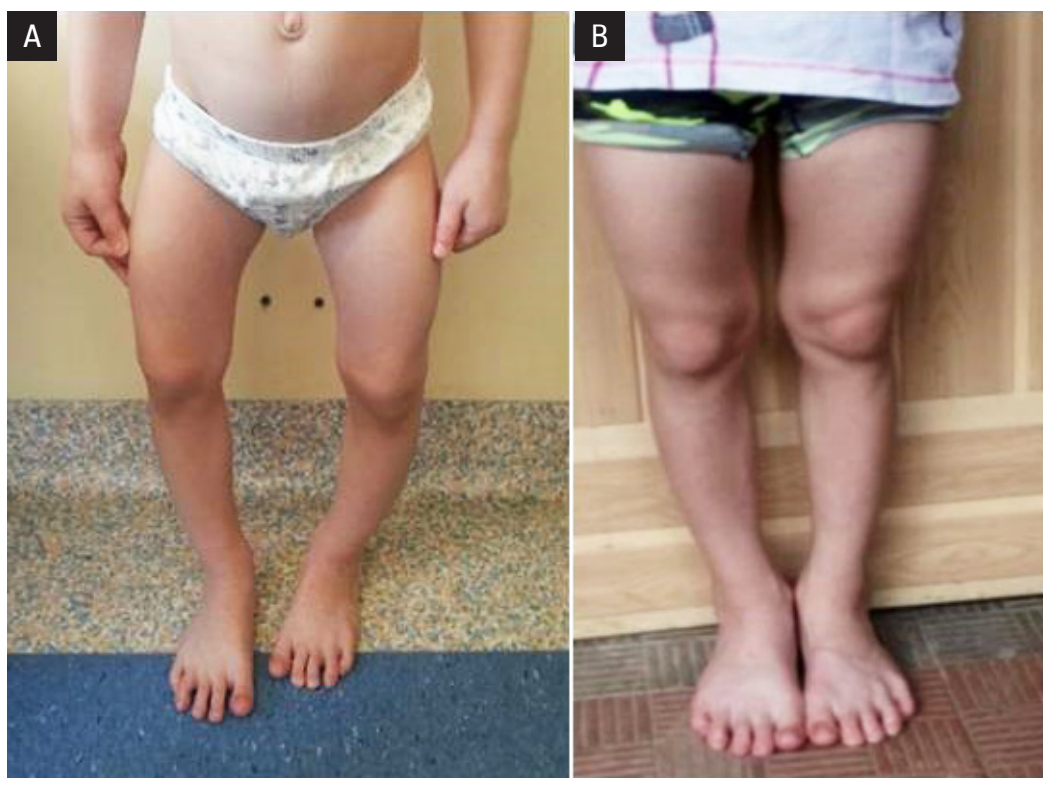

Figure 2. Lower limbs of Patient No. 1. Bowing of the lower limbs at age 3 years and 3 months (A) and the current status at age 9 years and 7 months $(\mathbf{B})$

Table 2. Auxological parameters of patients treated with recombinant human growth hormone (rhGH)

\begin{tabular}{lcccccccc}
\hline Patient & Sex & $\begin{array}{c}\text { Age at the time } \\
\text { of HR diagnosis } \\
\text { [years, months] }\end{array}$ & $\begin{array}{c}\text { Age at the onset } \\
\text { of rhGH therapy } \\
\text { [years, months] }\end{array}$ & $\begin{array}{c}\text { Current age } \\
\text { [years, months] }\end{array}$ & $\begin{array}{c}\text { HtSDS at the } \\
\text { onset of rhGH } \\
\text { therapy }\end{array}$ & $\begin{array}{c}\text { PAH at the onset } \\
\text { of rhGH therapy } \\
\text { [cm] }\end{array}$ & $\begin{array}{c}\text { Current } \\
\text { HtSDS }\end{array}$ & $\begin{array}{c}\text { Current } \\
\text { PAH } \\
\text { [cm] }\end{array}$ \\
\hline 1 & Female & $23 / 12$ & $69 / 12$ & $97 / 12$ & -3.4 & 149.7 & -3.0 & 152.6 \\
\hline 2 & Female & 7 & $106 / 12$ & $134 / 12$ & -2.0 & 153.6 & -2.2 & 152.6 \\
\hline 3 & Male & $23 / 12$ & $49 / 12$ & 8 & -3.1 & 164.8 & -1.8 & 168 \\
\hline
\end{tabular}

HtSDS — height standard deviation score; PAH — predicted adult height

and adult height prediction. In one patient (No. 2), after nearly 3 years of rhGH treatment, the height deficit and the predicted adult height were slightly worse than they were at the starting point of the therapy. The auxological details of these patients are given in Table 2 and on growth charts (Fig. 3A-C).

\section{Molecular findings}

In 10 out of 11 patients studied, PHEX gene mutations were found, except for Patient No. 4, in whom only one known polymorphism in intron 15 (c.1646-46T >C, g.180417T > C, rs3213493) was detected and described as of unknown clinical significance. Unfortunately, we were not able to sequence the entirety of exons 12 and 19.

In 2 of the patients, we detected 2 novel mutations (Fig. 4): c.325_326dupCA, N110Ifs*7 in exon 3 in Patient No. 1 and her affected father, and c.899_900delTG, M300Kfs* 4 in exon 8 in Patient No. 11. In 1 of these patients a novel mutation coexisted with a known polymorphism: c.1769-10C > T, rs3752433 in intron 17 (No. 11).
In one patient (No. 5), a novel deletion of exon 14 and two polymorphisms were detected: a known polymorphism in intron 15 (c.1646-46T >C, g.180417T >C, rs3213493) and a novel polymorphism (g.189156C $>$ T) in intron 17, both of which may lead to aberrant splicing of the PHEX transcript and aberrant function of the PHEX protein (sequencing of the entire exon 19 was unsuccessful). This novel deletion is not shown in Fig. 4.

Moreover, in the remaining patients, known mutations were observed: c. $663+1 \mathrm{G}>\mathrm{T}$ in intron 5 in 2 siblings (No. 8 and No. 9) and their affected mother [19], and c. $1483-1 G>A$ in intron 13 in 2 other siblings (No. 6 and No. 7) and their affected mother [20].

In Patient No. 2, the c. $1645+1 \mathrm{G}>\mathrm{A}$ mutation in intron 15 coexisted with the polymorphism c.1769-10C $>$ T, rs3752433 in the splicing site of intron 17. Both DNA changes, which may cause aberrant splicing of the PHEX transcript, were also found in the girl's affected mother. In Patient No. 3, c.1801_2250del encompassing exon 17-22, which leads to partial loss of the gene, was present. 

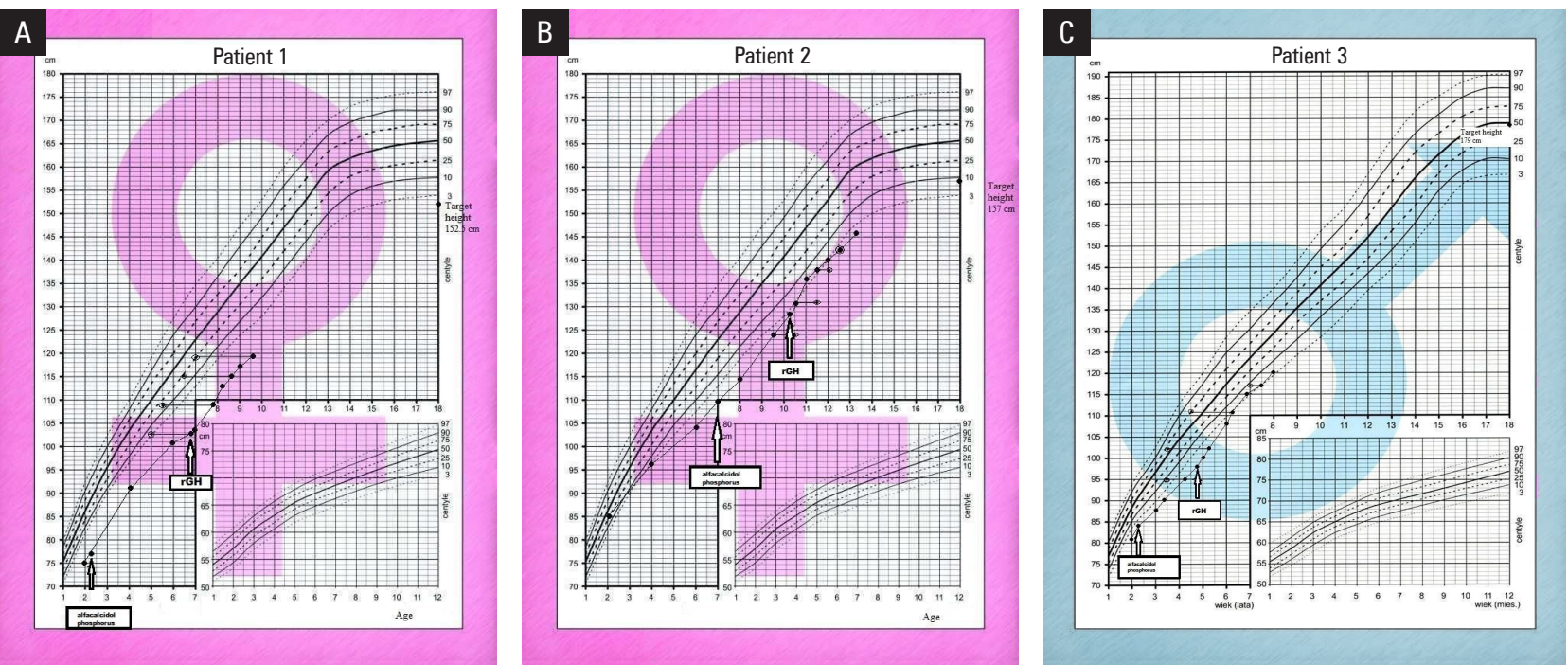

Figure 3. Growth charts of patients treated with recombinant growth factor $(r G H)$. A. Patient No. 1; B. Patient No. 2 ; C. Patient No. 3

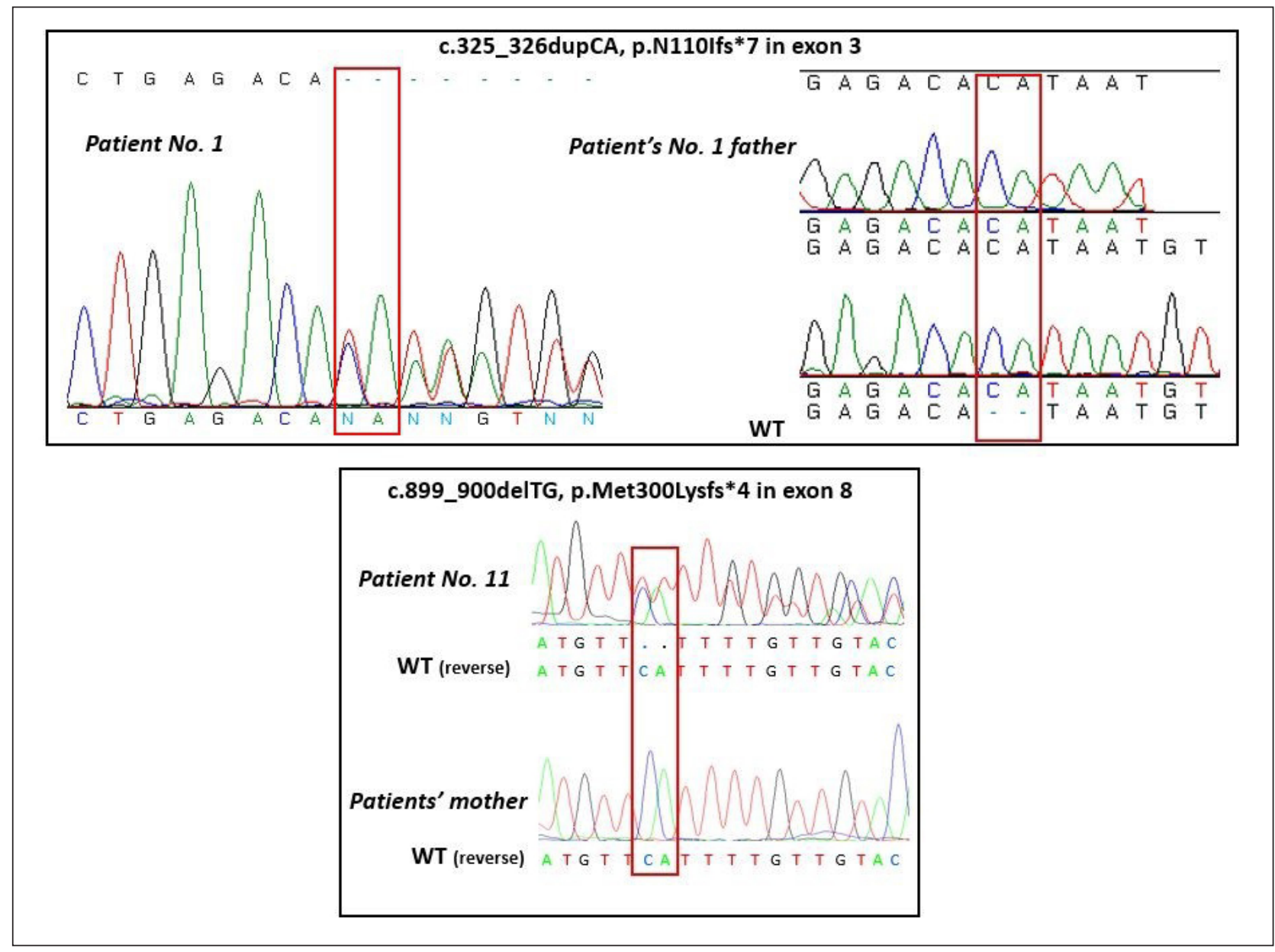

Figure 4. Novel mutations found in the analysed patients. The figure shows only 2 point mutations found in Patients 1 and 11, except for Patient No. 5, in which a deletion of exon 14 was found. Polymorphisms are not shown

In Patient No. 10, c.871C > T, p.R291* in exon 8 was found. The mutation leads to the formation of a prema- ture stop codon and premature termination of PHEX protein translation. 
Table 3. Genetic characteristics of the patients. In patient No. 1, a known c.C716>T, p.T239M heterozygous polymorphism (rs7955866) in exon 3 of FGF23 was found, which was absent in the patient's father. The FGF23 gene was intact in patients Nos. 2-5; patients Nos. 6-11 were not tested for FGF23

\begin{tabular}{|c|c|}
\hline Patient No. & PHEX \\
\hline 1. & $\begin{array}{l}\text { A novel heterozygous mutation (c.325_326dupCA, N110lfs*7) in exon } 3 \text {. This variant was found in neither the ExAC } \\
\text { nor the } 1000 \mathrm{G} \text { database and was also present in the patient's affected father. The mutation causes a frameshift and premature } \\
\text { termination of PHEX protein translation }\end{array}$ \\
\hline 2. & $\begin{array}{l}\text { A known heterozygous splicing mutation (c.1645+1G }>\text { A) in intron } 15 \text { and a heterozygous polymorphism }(c .1769-10 \mathrm{C}>\mathrm{T} \text {, } \\
\text { rs3752433) in the splice site of intron 17. Both DNA changes, which may cause aberrant splicing of the PHEX transcript, } \\
\text { were also found in the girl's affected mother }\end{array}$ \\
\hline 3. & A known hemizygous deletion (c.1801_2250del) leading to partial loss of the PHEX gene (exon 17 to exon 22) \\
\hline 4. & $\begin{array}{l}\text { A known polymorphism in intron } 15 \text { (c.1646-46T>C, g.180417T>C, rs3213493), which might lead to aberrant splicing } \\
\text { of the PHEX transcript and aberrant function of the PHEX protein (sequencing of the entire exon } 12 \text { and } 19 \text { was unsuccessful) }\end{array}$ \\
\hline 5. & $\begin{array}{l}\text { A novel deletion of exon } 14 \text { and two polymorphisms were detected: a known polymorphism in intron } 15 \text { (c.1646-46T }>\text { C, } \\
\text { g.180417T }>\text { C, rs3213493) and a novel polymorphism (g.189156C }>\text { T) in intron 17, both of which may lead to aberrant } \\
\text { splicing of the PHEX transcript and aberrant function of the PHEX protein (sequencing of the entire exon } 19 \text { was unsuccessful) }\end{array}$ \\
\hline 6. & $\begin{array}{l}\text { A known hemizygous mutation (c.1483-1G>A) in intron } 13 \text { leading to changes in the transcription of the PHEX gene } \\
\text { (also present in the patient's affected mother and younger sister (Patient No. 7) [33] }\end{array}$ \\
\hline 8. & $\begin{array}{l}\text { A known hemizygous mutation (c.663+1G }>\mathrm{T} \text { ) in intron } 5 \text { [32] and a known polymorphism }(\mathrm{c} .849+3 \mathrm{~A}>\mathrm{G}, \mathrm{rs} 200585038 \text { ) } \\
\text { in intron 7. Both mutations lead to aberrant splicing of the PHEX transcript and aberrant function of the PHEX protein. } \\
\text { Both mutations were present in the patient's affected mother and younger sister (Patient No 9) }\end{array}$ \\
\hline 10. & $\begin{array}{l}\text { A known heterozygous nonsense mutation (c.871C }>\text { T, p.R291X) in exon } 8 \text { leading to the formation of a premature stop codon } \\
\text { and premature termination of translation of the PHEX protein }\end{array}$ \\
\hline 11. & $\begin{array}{l}\text { A novel heterozygous mutation (c.899_900delTG) in exon 8, M300Kfs*4, a splicing mutation leading to a frameshift } \\
\text { and premature termination of the PHEX transcript and a known polymorphism c.1769-10C }>\text { T, rs } 3752433 \text { in intron } 17\end{array}$ \\
\hline
\end{tabular}

In one patient (No. 4), we found only one known polymorphism in intron 15; namely, c.1646-46T $>$ C, g.180417T >C, rs3213493. The FGF23 gene was intact, which suggests that HR in this case is caused by mutations in genes other than PHEX and FGF23.

Because HR can be caused by mutations in other genes a mutational analysis of FGF23 was performed in the selected patients (Nos. 1-5), but we did not find any pathogenic variants in any of them. In one patient (No. 1), we detected a known c.C716>T, p.T239M heterozygous polymorphism in exon 3 rs7955866 (which was absent in the patient's affected father), without clinical significance. Thus, we concluded that the identified novel mutation c.325_326dupCA, N110Ifs*7 in exon 3 of the PHEX gene is a molecular cause of HR in this family. In patients Nos. 6-11, the FGF23 gene was not tested because we did not have funds for further analysis, and the molecular background of HR was confirmed by mutations in PHEX gene.

The molecular results for the cohort are presented in Table 3.

\section{Discussion}

\section{Clinical picture}

The time of HR diagnosis was relatively early; however, it was late despite a positive family history in four patients. Most children are diagnosed with X-linked hypophosphataemia in the first year of life, provided that there is a known family history of the disorder [2]. Children presenting de novo HR symptoms are usually detected when poor weight gain and growth coexisting with progressive bowing of legs are observed [21]. Our cases show that the genetic counselling of affected families, and education of parents and general practitioners play a very important role in improving patient health and well-being. In the presented patients with late diagnosis and positive family history, the family members were not aware that rickets might be inheritable and that early diagnosis and treatment initiation improve the disease's outcome. Unfortunately, in three patients, the late diagnosis was associated with the necessity to perform several orthopaedic surgeries of the lower limbs. In affected mothers of three patients with a late diagnosis, the molecular tests were performed along with the genetic analysis of the children, and they were informed about the inheritance of the disease afterwards.

The dominant dysfunction in our patients was deformation of the legs (especially genu varum), which is in line with the current literature [2, 22]. General softening of the bone due to defective mineralisation, together with the weight of the child and muscles pulling on weak bones, led to lower limb bending [23]. The cancellous compartment of long bones, particularly the tibia, is undermineralised [24]. Some studies 
show that females with XLHR have less related bone involvement than males [23]. Whyte et al. [25] failed to show any evidence for genetic heterogeneity or for effects based on gender, race, anticipation, or parent of origin on XLHR expression in children. Our case study also does not allow us to say that boys suffer in a more severe way. Early conventional medical treatment may prevent or reduce long-bone deformities and facilitate the healing of pseudofractures [26]. The objective in pharmacological treatment should be attained after 3-4 years of leg straightening, which is $1 \mathrm{~cm}$ in intercondylar distance every 6 months [22]. Unfortunately, early diagnosis and supplementation with phosphorus and alphacalcidol did not guarantee the reduction of skeletal abnormalities in our studied group. The patient's compliance should also be taken into account, especially because the phosphorus intake can be problematic. Oral phosphate supplements should be taken 4-5 times daily due to rapid absorption and excretion. The oral intake of phosphorus leads to a rapid increase in serum and reaches the baseline level within 1.5 hours [27]. The compliance of phosphorus intake in the studied group, especially at the beginning of therapy, could be not satisfactory, but evident irregularity in the treatment was not registered.

Almost all of our patients were short at diagnosis and during therapy. Only one girl (Patient No. 10) had a normal height (current htSDS 0.2) with the target height calculated on the basis of her parents' height estimated to be $167 \mathrm{~cm}$. She is overweight, which probably has a promoting impact on her growth. Her height standard deviation score improved on conventional treatment. Somatic growth in obese patients appears to be mainly GH-independent [28]. Increased insulin action on the IGF-1 receptor [29] and insulin resistance suppressing IGF-binding proteins leading to greater IGF-1 bioavailability [30] are the mechanisms stimulating the growth process. Altered sex steroid concentrations and adipokines released by the adipose tissue could also play a role [28]. Leptin appears to be an additional factor for stimulating growth [31]. Furthermore, increased aromatisation of androgens into oestrogens in adipose tissue may be another mechanism regulating growth [32]. Short stature in HR is secondary to growth restriction of the lower extremities rather than generalised growth failure [33]. The degree of growth impairment is not dependent on the magnitude of hypophosphataemia or the extent of leg bowing, and the chronic administration of phosphate supplements and alphacalcidol is usually not able to normalise the height [34]. Adults with XLHR have a final height that is significantly reduced by up to $20 \mathrm{~cm}$, with a mean htSDS of -1.9 [352]. Adults who have begun earlier treatment with phosphate and calcitriol manage to grow taller despite having a similar degree of hypophosphataemia [36].

Our presented group is heterogeneous, and because of the different types of therapy and sometimes a short observation period, it is hard to clearly specify the conclusions regarding growth, time of diagnosis and laboratory findings.

In two out of three patients with an early diagnosis of $\mathrm{HR}$ and treated with rhGH, a reduction in the height deficit with improved adult height prediction and reduction in lower limb bowing were observed. One girl with a late diagnosis, who started rhGH therapy after pubertal onset, did not improve her height. It seems that the time of therapy introduction is the key point. Recombinant human growth hormone influences patient growth as well as bone mineral metabolism. The GH-related increase in phosphate reabsorption is thought to be mediated by IGF-1. In healthy individuals, the latter increases the renal production of $1,25(\mathrm{OH}) 2$ vitamin D3 as well as intestinal and renal phosphate absorption $[36,37]$. In view of the GH-induced rise in IGF-1 serum levels, this pathway seems to be still operational in XLHR, although this was not sufficient to normalise TmP/GFR (tubular maximum reabsorption of $\mathrm{PO}_{4} /$ /glomerular filtration rate) and serum phosphate levels [13]. There are many studies concerning the usefulness of rhGH therapy in XLHR. The randomised study of Živičnjak et al. [13] resulted in a linear growth increase (+1.1 height SDS) in 16 short prepubertal patients with XLHR treated with rhGH for three years. Rothenbuhler et al. [38] also proved that two-year rhGH treatment is effective in treating short stature in XLHR children and that prepubertal children respond better to rhGH. However, the studies are still based on small groups, and there are doubts as to whether rhGH treatment has a positive impact on body proportions.

The initial dominant biochemical abnormality in our patients was hypophosphataemia and elevated alkaline phosphatase, which is a typical abnormality found in XLHR patients occurring in the first months of their life, as a result of FGF23-driven phosphaturia [24]. Urine phosphorus excretion was decreased, and TRP was normal at the time of diagnosis/during the first stay at the department in most patients. Low phosphorus excretion is a result of low chronic hypophosphataemia. Tubular reabsorption of phosphate improves as serum phosphorus and the filtered load of $\mathrm{PO}_{4}$ declines, and the calculation of the tubular maximum reabsorption of $\mathrm{PO}_{4}(\mathrm{TmP} / \mathrm{GFR})$ is needed to identify the mutant renal phenotype [24].

In one of our patients, a Chiari type 1 malformation was revealed. XLHR children are at risk of developing cranial vault and craniovertebral anomalies, such as early closure of the cranial sutures and Chiari type 
1 malformation. The association of craniosynostosis to rickets has been documented as early as 1964, and several reports of scaphocephaly in patients with rickets have been described [39]. Rothenbuhler et al. [40] found that $59 \%$ of XLHR children had a complete or partial fusion of the sagittal suture, and $25 \%$ of XLHR children showed protrusion of the cerebellar tonsils. A history of dental abscesses was related to craniosynostosis, which in turn was associated with abnormal descent of cerebellar tonsils. Only 2 patients from that study showed neurological symptoms. Our patient presented deformation of the head with frontal bossing and had a chronic problem with dental abscesses. Although he had an episode of seizures, there were no pathological signs in neurological evaluation, and epilepsy was finally excluded.

There are several limitations to our study. The first is the size of the study group and the relatively short time of observation. As bones' mineralisation continues beyond the period where the final height is reached, it would be valuable to extend the study to a longer period. Finally, we cannot exclude periodic non-compliance with phosphorus and alphacalcidol intake in some of our HR patients, affecting the results.

\section{Molecular analysis}

The PHEX gene consists of 22 exons [41, 42, 43, 44] and is translated into a 749 amino acid protein (https:// www.uniprot.org/uniprot/P78562). Extensive mutation analysis showed that the spectrum of the PHEX gene mutations is very wide, including nonsense, missense, and splicing site mutations, as well as insertions and deletions in different positions. Current data from the Human Gene Mutation Database (HGMD) (http://www. hgmd.cf.ac.uk/ac/index.php; access date: 09.10.2020) include 588 mutations in PHEX. The most common types of mutations are missense/nonsense mutations whereas other types are less common. There are no hot-spot mutations, which makes the analysis more time-consuming and expensive. Moreover, the gene undergoes alternative splicing, which may lead to the production of several active forms of the PHEX protein (https://www.genecards.org/cgi-bin/carddisp. pl?gene $=\mathrm{PHEX})$. It is possible that some of them might be involved in bone turnover and dentin formation, whereas others may play an important role in renal phosphate uptake and vitamin D3 metabolism. Considering that splice prediction programs cannot reliably predict the outcome of splice mutations, the effects of mutations in such, probably active alternative forms of PHEX, are very difficult to foresee.

There is also no clear genotype-phenotype correlation of the PHEX gene mutation in XLHR, and the severity of clinical symptoms does not strictly depend on the type of the PHEX gene mutation and its location. However, some trends in families with XLHR may be observed in the literature. For example, Popowska et al. [45] described 59 patients with XLHR and observed that hearing defects and dental abnormalities were correlated with mutations located at the beginning of the gene, whereas mutations located in its terminal region were associated with increased head length. Other studies showed more severe skeletal malformations in patients with nonsense mutations leading to a truncation of the PHEX protein [41] or with a mutation in the region encoding for its $C$-terminal part [42]. Lower 1,25(OH)2D3 levels and TRP have also been found in patients with nonsense mutations, which suggest that the phenotypic severity of the disease may be dependent on the type of PHEX mutation [46]. However, further and thorough molecular studies are needed to confirm this hypothesis.

Several studies have shown that elevated levels of circulating FGF23 in serum were associated with PHEX mutations in XLHR patients [47] and suggest that overexpression of FGF23 might stand for an ultimate linkage in the pathogenesis of XLHR. Unfortunately, we were unable to determine the serum level of FGF23 due to a lack of initial patient serum samples.

\section{Conclusions}

The study presents the clinical picture and biochemical profile of patients with XLHR. Three novel mutations in the PHEX gene responsible for HR are reported. Early diagnosis and implementation of conventional treatment and rhGH can improve patient height and minimise bone deformities. Molecular analysis is necessary to confirm the clinical diagnosis of HR and conduct appropriate genetic counselling in families with HR patients.

\section{Authors' contributions}

M.O.M. and A.R contributed equally to this paper.

All the authors have read the manuscript, accept responsibility for its entire content, and approve its submission. M.O.M - study concept and design, clinical evaluation of the patients, manuscript drafting; A.R. - study concept and design, molecular genetic studies, analysis and interpretation of molecular data, manuscript drafting, funding procurement; ZK — clinical evaluation of the patients; D.J. - molecular genetic studies, analysis and interpretation of molecular data; K.H.C.H. - clinical evaluation of the patients, analysis and interpretation of molecular data, critical revision of the manuscript for important intellectual content; M.N. - study concept and design, clinical evaluation of the patients, critical revision of the manuscript for 
important intellectual content, funding procurement, study supervision.

\section{Conflicts of interest}

All authors have no conflicts of interest.

\section{Informed consent}

All patients and their parents were informed about the research, and written parental consent was obtained for the molecular analysis and publication of the data.

\section{Availability of data and material}

This manuscript contains previously unpublished data. The data support the findings of this study and are available from the corresponding author upon reasonable request.

\section{Code availability}

Not applicable.

\section{Funding}

This work was supported by funds from the Department of Paediatric Endocrinology and Rheumatology of Poznan University of Medical Sciences (No. 502-01-01104118-06037 to Marek Niedziela) and by a Research Grant from the Department of Paediatric Endocrinology and Rheumatology of Poznan University of Medical Sciences (No. 502-1401104118-09627 to Aleksandra Rojek).

\section{References}

1. Angham AM, Rajaa A. Types of rickets. Ann Orthop Rheumatol. 2017; 5: 1085 .

2. Carpenter TO, Imel EA, Holm IA, et al. A clinician's guide to Xlinked hypophosphatemia. J Bone Miner Res. 2011; 26(7): 1381-1388, doi: 10.1002/jbmr.340, indexed in Pubmed: 21538511.

3. DeLucia MC, Mitnick ME, Carpenter TO. Nutritional rickets with normal circulating 25-hydroxyvitamin D: a call for reexamining the role of dietary calcium intake in North American infants. J Clin Endocrinol Metab. 2003; 88(8): 3539-3545, doi: 10.1210/jc.2002-021935, indexed in Pubmed: 12915633.

4. Alon US. Hypophosphatemic vitamin D-resistant rickets. In: Favus MJ. ed. Primer on the Metabolic Bone Diseases and Disorders of Mineral Metabolism. American Society for Bone and Mineral Research, Washington, DC 2006: 342-345.

5. Mäkitie O, Doria A, Kooh SW, et al. Early treatment improves growth and biochemical and radiographic outcome in X-linked hypophosphatemic rickets. J Clin Endocrinol Metab. 2003; 88(8): 3591-3597, doi: 10.1210/jc.2003-030036, indexed in Pubmed: 12915641.

6. Carpenter TO, Insogna KL, Zhang JH, et al. Circulating levels of soluble klotho and FGF23 in X-linked hypophosphatemia: circadian variance, effects of treatment, and relationship to parathyroid status. J Clin Endocrinol Metab. 2010; 95(11): E352-E357, doi: 10.1210/jc.2010-0589, indexed in Pubmed: 20685863.

7. FDA (2018) FDA news release: FDA approves first therapy for rare inherited form of rickets, X-linked hypophosphatemia. https://www.fda. gov/NewsEvents/Newsroom/PressAnnouncements/ucm604810.htm. Accessed 25 May 2018 (Accessed 25 May 2018).

8. Lamb YN. Burosumab: First Global Approval. Drugs. 2018; 78(6): 707-714, doi: 10.1007/s40265-018-0905-7, indexed in Pubmed: 29679282.

9. Patel L, Clayton PE, Brain C, et al. Acute biochemical effects of growth hormone treatment compared with conventional treatment in familial hypophosphataemic rickets. Clin Endocrinol (Oxf). 1996; 44(6): 687-696, doi: 10.1046/j.1365-2265.1996.740561.x, indexed in Pubmed: 8759181.
10. Haffner D, Wühl E, Blum WF, et al. Disproportionate growth following long-term growth hormone treatment in short children with X-linked hypophosphataemia. Eur J Pediatr. 1995; 154(8): 610-613, doi: 10.1007/BF02079060, indexed in Pubmed: 7588957.

11. Saggese G, Baroncelli G, Bertelloni S, et al. Long-term growth hormone treatment in children with renal hypophosphatemic rickets: Effects on growth, mineral metabolism, and bone density. J Pediatr. 1995; 127(3): 395-402, doi: 10.1016/s0022-3476(95)70070-6, indexed in Pubmed: 7658269.

12. Reusz GS, Miltényi G, Stubnya G, et al. X-linked hypophosphatemia: effects of treatment with recombinant human growth hormone. Pediatr Nephrol. 1997; 11(5): 573-577, doi: 10.1007/s004670050340, indexed in Pubmed: 9323282.

13. Živičnjak M, Schnabel D, Staude H, et al. Hypophosphatemic Rickets Study Group of the Arbeitsgemeinschaft für Pädiatrische Endokrinologie and Gesellschaft für Pädiatrische Nephrologie. Three-year growth hormone treatment in short children with X-linked hypophosphatemic rickets: effects on linear growth and body disproportion. J Clin Endocrinol Metab. 2011; 96(12): E2097-E2105, doi: 10.1210/jc.2011-0399, indexed in Pubmed: 21994957.

14. Palczewska I, Niedźwiecka Z. Wskaźniki rozwoju somatycznego dzieci i młodzieży warszawskiej. Med Wieku Rozw. 2011; 5: 18-118.

15. Greulich W, Pyle S. Radiographic Atlas of Skeletal Development of the Hand and Wrist. Stanford University Press, Stanford 1995: Stanford.

16. Bayley N, Pinneau S. Tables for predicting adult height from skeletal age: Revised for use with the greulich-pyle hand standards. J Pediatr. 1952; 40(4): 423-441, doi: 10.1016/s0022-3476(52)80205-7, indexed in Pubmed: 14918032 .

17. Francis F, Strom TM, Hennig S, et al. Genomic organization of the human PEX gene mutated in X-linked dominant hypophosphatemic rickets. Genome Res. 1997; 7(6): 573-585, doi: 10.1101/gr.7.6.573, indexed in Pubmed: 9199930.

18. Larsson T, Yu X, Davis SI, et al. A novel recessive mutation in fibroblast growth factor-23 causes familial tumoral calcinosis. J Clin Endocrinol Metab. 2005; 90(4): 2424-2427, doi: 10.1210/jc.2004-2238, indexed in Pubmed: 15687325.

19. Kang YE, Hong JH, Kim J, et al. A Novel PHEX Gene Mutation in a Patient with Sporadic Hypophosphatemic Rickets. Endocrinol Metab (Seoul). 2014; 29(2): 195-201, doi: 10.3803/EnM.2014.29.2.195, indexed in Pubmed: 25031893.

20. Kinoshita Y, Saito T, Shimizu Y, et al. Mutational analysis of patients with FGF23-related hypophosphatemic rickets. Eur J Endocrinol. 2012; 167(2): 165-172, doi: 10.1530/EJE-12-0071, indexed in Pubmed: 22577109.

21. Stickler GB. Familial hypophosphatemic vitamin D resistant rickets. The neonatal period and infancy. Acta Paediatr Scand. 1969; 58(3): 213-219, doi: 10.1111/j.1651-2227.1969.tb04709.x, indexed in Pubmed: 5783409.

22. Linglart A, Biosse-Duplan M, Briot K, et al. Therapeutic management of hypophosphatemic rickets from infancy to adulthood. Endocr Connect. 2014; 3(1): R13-R30, doi: 10.1530/EC-13-0103, indexed in Pubmed: 24550322.

23. Pavone V, Testa G, Gioitta Iachino S, et al. Hypophosphatemic rickets: etiology, clinical features and treatment. Eur J Orthop Surg Traumatol. 2015; 25(2): 221-226, doi: 10.1007/s00590-014-1496-y, indexed in Pubmed: 24957364

24. Bitzan M, Goodyer PR. Hypophosphatemic Rickets. Pediatr Clin North Am. 2019; 66(1): 179-207, doi: 10.1016/j.pcl.2018.09.004, indexed in Pubmed: 30454743.

25. Whyte MP, Schranck FW, Armamento-Villareal R. X-linked hypophosphatemia: a search for gender, race, anticipation, or parent of origin effects on disease expression in children. J Clin Endocrinol Metab. 1996; 81(11): 4075-4080, doi: 10.1210/jcem.81.11.8923863, indexed in Pubmed: 8923863.

26. Glorieux FH, Marie PJ, Pettifor JM, et al. Bone response to phosphate salts, ergocalciferol, and calcitriol in hypophosphatemic vitamin D-resistant rickets. N Engl J Med. 1980; 303(18): 1023-1031, doi: 10.1056/NEJM198010303031802, indexed in Pubmed: 6252463.

27. Bettinelli A, Bianchi M, Mazzucchi E, et al. Acute effects of calcitriol and phosphate salts on mineral metabolism in children with hypophosphatemic rickets. The Journal of Pediatrics. 1991; 118(3): 372-376, doi: 10.1016/s0022-3476(05)82149-3.

28. De Leonibus C, Marcovecchio ML, Chiarelli F. Update on statural growth and pubertal development in obese children. Pediatr Rep. 2012; 4(4): e35, doi: 10.4081/pr.2012.e35, indexed in Pubmed: 23355935.

29. Geffner ME. The growth without growth hormone syndrome. . Endocrinol Metab Clin North Am . 1996; 25(3): 649-663, doi: 10.1016/s0889-8529(05)70345-5, indexed in Pubmed: 8879991.

30. Ballerini MG, Ropelato MG, Domené HM, et al. Differential impact of simple childhood obesity on the components of the growth hormone-insulin-like growth factor (IGF)-IGF binding proteins axis. J Pediatr Endocrinol Metab. 2004; 17(5): 749-757, doi: 10.1515/jpem.2004.17.5.749, indexed in Pubmed: 15237710. 
31. Shalitin S, Phillip M. Role of obesity and leptin in the pubertal process and pubertal growth--a review. Int J Obes Relat Metab Disord. 2003; 27(8): 869-874, doi: 10.1038/sj.ijo.0802328, indexed in Pubmed: 12861226

32. Burt Solorzano CM, McCartney CR. Obesity and the pubertal transition in girls and boys. Reproduction. 2010; 140(3): 399-410, doi: 10.1530/REP-10-0119, indexed in Pubmed: 20802107.

33. McNair S, Stickler G. Growth in Familial Hypophosphatemic Vitamin-D-Resistant Rickets. N Engl J Med. 1969; 281(10): 511-516, doi: 10.1056/nejm196909042811001, indexed in Pubmed: 5800510.

34. Fuente R, Gil-Peña H, Claramunt-Taberner D, et al. X-linked hypophosphatemia and growth. Rev Endocr Metab Disord. 2017; 18(1): 107-115 doi: 10.1007/s11154-017-9408-1, indexed in Pubmed: 28130634.

35. Beck-Nielsen SS, Brusgaard K, Rasmussen LM, et al. Phenotype presentation of hypophosphatemic rickets in adults. Calcif Tissue Int. 2010; 87(2): 108-119, doi: 10.1007/s00223-010-9373-0, indexed in Pubmed: 20524110.

36. Caverzasio J, Bonjour JP. Characteristics and regulation of Pi transport in osteogenic cells for bone metabolism. Kidney Int. 1996; 49(4): 975-980, doi: 10.1038/ki.1996.138, indexed in Pubmed: 8691747.

37. Hirschberg R, Hirschberg R, Hirschberg R, et al. Physiological effects of growth hormone and insulin-like growth factor I on the kidney. Miner Electrolyte Metab. 1990; 16(1): 82-88, indexed in Pubmed: 2182998.

38. Rothenbuhler A, Esterle L, Gueorguieva I, et al. Two-year recombinant human growth hormone (rhGH) treatment is more effective in pre-pubertal compared to pubertal short children with X-linked hypophosphatemic rickets (XLHR). Growth Horm IGF Res. 2017; 36: 11-15, doi: 10.1016/j.ghir.2017.08.001, indexed in Pubmed: 28822957.

39. Reilly BJ, Leeming J, Fraser D. Craniosynostosis in the rachitic spectrum. J Pediatr. 1964; 64(3): 396-405, doi: 10.1016/s0022-3476(64)80192-x, indexed in Pubmed: 14130713.

40. Rothenbuhler A, Fadel N, Debza $Y$ et al. High Incidence of Crania Synostosis and Chiari I Malformation in Children With X-Linked Hy- pophosphatemic Rickets (XLHR). J Bone Miner Res. 2019; 34(3): 490-496, doi: 10.1002/jbmr.3614, indexed in Pubmed: 30352126.

41. Holm IA, Nelson AE, Robinson BG, et al. Mutational analysis and genotype-phenotype correlation of the PHEX gene in X-linked hypophosphatemic rickets. J Clin Endocrinol Metab. 2001; 86(8): 3889-3899, doi: 10.1210/jcem.86.8.7761, indexed in Pubmed: 11502829.

42. Song HR, Park JW, Cho DY, et al. PHEX gene mutations and genotype-phenotype analysis of Korean patients with hypophosphatemic rickets. J Korean Med Sci. 2007; 22(6): 981-986 doi: 10.3346/jkms.2007.22.6.981, indexed in Pubmed: 18162710.

43. A gene (PEX) with homologies to endopeptidases is mutated in patients with X-linked hypophosphatemic rickets. The HYP Consortium. Nat Genet. 1995; 11(2): 130-136, doi: 10.1038/ng1095-130, indexed in Pubmed: 7550339.

44. Filisetti D, Ostermann G, von Bredow M, et al. Non-random distribution of mutations in the PHEX gene, and under-detected missense mutations at non-conserved residues. Eur J Hum Genet. 1999; 7(5): 615-619, doi: 10.1038/sj.ejhg.5200341, indexed in Pubmed: 10439971.

45. Popowska E, Pronicka E, Sułek A, et al. X-linked hypophosphatemia in Polish patients. 2. Analysis of clinical features and genotype-phenotype correlation. J Appl Genet. 2001; 42(1): 73-88, indexed in Pubmed: 14564066

46. Morey M, Castro-Feijóo L, Barreiro J, et al. Genetic diagnosis of X-linked dominant Hypophosphatemic Rickets in a cohort study: tubular reabsorption of phosphate and 1,25(OH)2D serum levels are associated with PHEX mutation type. BMC Med Genet. 2011; 12: 116, doi: 10.1186/1471-2350-12-116, indexed in Pubmed: 21902834.

47. Saito $\mathrm{H}$, Kusano $\mathrm{K}$, Kinosaki $\mathrm{M}$, et al. Human fibroblast growth factor-23 mutants suppress $\mathrm{Na}+$-dependent phosphate co-transport activity and 1alpha,25-dihydroxyvitamin D3 production. J Biol Chem. 2003; 278(4): 2206-2211, doi: 10.1074/jbc.M207872200, indexed in Pubmed: 12419819. 